\title{
Student Satisfaction with Using Online Discussion Forums at Saudi Universities
}

\author{
Majed Gharmallah Alzahrani ${ }^{1, *}$ \\ ${ }^{1}$ Faculty of Education, University of Jeddah, Saudi Arabia \\ "Correspondence: Faculty of Education, University of Jeddah, 21454, P.O.BOX: 15758, Jeddah, Saudi Arabia. \\ E-mail:mgalzahrani@uj.edu.sa
}

Received: February 13, 2017

Accepted: February 21, 2017 Online Published: February 28, 2017

doi:10.5430/wje.v7n2p1

URL: https://doi.org/10.5430/wje.v7n2p1

\begin{abstract}
This study aims to investigate student satisfaction with using online discussion forums (ODFs). It also aims to examine the relationships between student satisfaction with using ODFs and student demographics as well as with their experience with ICT and online education. Data are collected from 2171 students from four leading universities at Saudi Arabia through using an online survey. Overall, the results indicate that students are satisfied with using ODFs in their learning. In addition, student satisfaction with using ODFs had significant relationships with the majority of student demographics and experience with ICT variables. Interestingly, all student experience with online education variables had significant and positive relationships with student satisfaction with using ODFs. However, factors such the availability of the Internet, preference of traditional learning, life commitments, and experience with ICT and online education may affect student satisfaction with using ODFs.
\end{abstract}

Keywords: student satisfaction; online discussion forums (ODFs); blended learning; Saudi Arabia

\section{Introduction}

Many universities around the world and in Saudi Arabia provide some courses either fully online or in blended learning environments. Mostly, this provision is made through what is known as learning management systems (LMSs) such as Blackboard, WebCT, Moodle and Desire2Learn. However, Blackboard is the most common platform used in Saudi universities (Colbran \& Al-Ghreimil, 2013). The platforms of these LMSs provide a variety of features, and one of the main features is online discussion forums (ODFs) or known as discussion boards. According to Alebaikan and Troudi (2010), ODFs are considered to be one of the major components of blended learning. In addition, using ODFs in blended learning environments can have positive effects on student learning (Alebaikan \& Troudi, 2010; AlMahamoud \& Elebiary, 2013; Alzahrani, 2017; Hamdan, 2014) and student satisfaction (AlJeraisy, Mohammad, Fayyoumi, \& Alrashideh, 2015; AlMahamoud \& Elebiary, 2013; Hamdan, 2014).

\section{Literature Review}

Satisfaction is considered to be one of the most important measures that determines the quality of online education and blended learning (Abou Naaj, Nachouki, \& Ankit, 2012; Kardo, 2015; M. Moore \& Kearsley, 2012). Regardless of which environment is used, the quality of the delivery of courses is crucial (Bolliger \& Wasilik, 2009). Student satisfaction is a fundamental requirement in the educational process. It is one of the five pillars of the Sloan Consortium's quality framework that could be used to evaluate the quality of asynchronous learning networks (ALNs) (J. C. Moore, 2005) or blended learning environments (Laumakis, Graham, \& Dziuban, 2009). Abou Naaj et al. (2012) asserted that in blended learning environments, student satisfaction "is a baseline requirement for successful implementation" (p. 185). In this study, student satisfaction refers to student pleasure derived from using ODFs as an educational tool in blended learning courses.

The literature indicated that the number of studies that have focused on evaluating student satisfaction with using ODFs in the Saudi higher education context appears to be limited. For example, Altaf (2013) investigated the level of satisfaction of students with using ODFs and other communication tools within e-learning platforms in four Saudi 
universities. He found that almost half of them were using ODFs and had high level of satisfaction with its usage. A more pertinent study was conducted by Alamro and Schofield (2012) to evaluate student satisfaction with using ODFs alongside traditional learning in Qassim Medical School. The study found that most of students were satisfied with using ODFs. The majority of students reported that they look forward to use ODFs again in future, enjoyed the ODFs' environment, and were motivated to use ODFs with traditional learning classes in a blended learning approach. Overall, the study indicated that participants were satisfied with using ODFs in their learning alongside traditional classes. In a similar context, an Arabic context, a study conducted by Shana (2009) also indicated that students were satisfied with using ODFs alongside traditional learning. All of the students involved in Shana's study (2009) reported that they would like to use ODFs in the future.

The literature review in the Saudi higher education context also showed that using ODFs in blended learning courses is likely to increase student satisfaction. For example, student satisfaction was found to be higher in blended learning environments that used ODFs than in the traditional learning environment (AlMahamoud \& Elebiary, 2013). The empirical investigation of AlMahamoud and Elebiary (2013) revealed that the higher satisfaction of students most likely was "impacted by the more active classroom teaching approach utilized in the blended course format." (p. 4658). AlMahamoud and Elebiary (2013) concluded that higher student satisfaction with blended learning courses is the result of "good learning" (p. 4658). More recently, AlJeraisy et al. (2015) asserted that ODFs "are effective learning tools that promote overall student satisfaction with the online experience and content of the course" (p. 256). Empirically, AlJeraisy et al. (2015) found that, in blended learning courses, students with access to ODFs were significantly more satisfied than students without access to this tool in terms of learning experience, interaction with academic staff and other students, and the ability of academic staff to engage them using the Moodle system.

Overall, the findings of these studies indicated that students were satisfied with using ODFs, particularly when they used ODFs as a supplementary pedagogical tool in blended learning courses in order to enhance traditional learning. However, none of these previous studies has investigated the relationships between student satisfaction with using ODFs in particular and student demographics or experience with ICT and online education. Internationally, the literature indicated that a number of studies have identified key factors that influence student satisfaction with using ODFs in fully online courses or in blended courses. For example, Lang and Costello (2009) discussed factors related to the role of instructor, student attitude, social presence, usefulness, and effectiveness of ODFs. Others focused on instructor presence (e.g., see Ladyshewsky, 2013) and interaction either with instructor or with peers as well as the clarity of design (e.g., see Swan, 2001; Swan \& Shih, 2005). However, very few studies have focused on the relationships between student satisfaction with using ODFs and student demographics or experience with ICT and online education (Jackson, 2014; Ryan, 2013). For example, Ryan (2013) found a statistical and positive relationship between student satisfaction with using ODFs and previous online courses, but no statistical relationships were found with computer expertise or study type. Although data regarding student age and gender were collected in Ryan's study (2013), the relationships of these variables with satisfaction with using ODFs were not reported. More recently, Jackson (2014) did not find significant differences in student satisfaction with using ODFs based on their gender, Grade point average (GPA), or age -18 to 24 and 25 and older, but found a significant difference based on the number of online courses students have taken either one or two courses or three or more courses.

To conclude, while studies in the Saudi higher education context regarding evaluating student satisfaction with using ODFs appear to be limited, the relationships between student satisfaction with using ODFs and student demographics or experience with ICT and online education seem to be undiscussed entirely. Accordingly, investigating student satisfaction with using ODFs and these relationships is critical for those who desire high quality learning environments.

\section{Research Questions of the Study}

The study addresses the following research questions:

1. How satisfied are students with using ODFs?

2. Is there any statistical relationship between student satisfaction and demographic variables?

3. Is there any statistical relationship between student satisfaction and experience with ICT?

4. Is there any statistical relationship between student satisfaction and experience with online education? 


\section{Methodology}

\subsection{Research Setting and Participants}

The setting for this study was four public universities located at different regions of the country. These universities were: Central Region University (CRU), Western Region University (WRU), Eastern Region University (ERU) and Southern Region University (SRU). These are pseudonyms as the identification of the universities' names is kept confidential due to ethical considerations. It should be highlighted that universities located at the north region of the country were not involved because either were recently established universities and/or have small population. However, the selected universities are from the largest universities in Saudi Arabia or within the regions they belong to. In addition, these universities were established during the second part of the last century.

Sampling for participants followed the saturation sampling technique, as all students' email addresses at the four universities were known to the universities. The saturation sampling technique is commonly used in universities as it eliminates coverage error, as every member is invited to participate (Sue \& Ritter, 2007). Hence, all students whose emails were registered on the databases of the targeted universities received the invitation email containing a given link that participants could follow to fill out the online survey. As a result, 2171 students completed the online survey.

\subsection{Instrument}

An online survey was designed for this study. It was divided into three main sections; demographic information, ICT use and experience, and student satisfaction with using ODFs. Items related to the satisfaction scale (eight items) were derived form from the literature (e.g., Alamro \& Schofield, 2012; Algahtani, 2011; Garnham \& Kaleta, 2002; Skelton, 2007). However, the assurance of the reliability of the student satisfaction scale is important (Pallant, 2011) and is a presupposed requirement for the measurement validity (Bryman, 2012). Therefore, internal consistency was examined through the indicator of Cronbach's alpha coefficient. The Cronbach's alpha coefficient value was 0.88 indicating that the student satisfaction scale was considered reliable (Bryman, 2012; Pallant, 2011). The survey provider "Smartsurvey" (www.smartsurvey.co.uk) was used to mount and deliver the survey online and to host it during the data collection process. This type of online survey is known as a web-based survey which "is designed as a web page and located on a host site where visitors to the site can access it" (Denscombe, 2007, p. 160). The online survey was available in Arabic and English languages.

\subsection{Analysis Procedures}

The Statistical Package for Social Sciences (SPSS v.20.0 package) was used in this study. The assumptions of parametric techniques including independency, normality and homogeneity (Carver \& Nash, 2012; Connolly, 2007; Field, 2009) were checked to ensure that they were not violated. Each participant received the invitation email and completed it through the given link, so the responses could be assumed to be independent. The sample size in this study resolved the assumption of normality of the distribution (Field, 2009; Pallant, 2011). The Levene's test was used to check the assumption of homogeneity and the result was not significant ( $>.05)$ for the satisfaction scale, confirming that the variance was equal across male and female groups for the four Saudi universities $F=.788, P$ $=.375$.

\section{Results}

\subsection{Demographic Information}

Table1 shows the demographic information of the 2171 students across the four Saudi universities.

Table1 shows that the majority of students were; affiliated to the Central Region University (CRU), females, undergraduates, studying on campus, Saudis, not working, and studying full time. It should be highlighted that about a third of students had not reported their program of study and the GPA as they might be were in the first semester of study in which they have not selected the program of study yet and the GPA has not been issued yet. In addition, almost two fifth of students were in the first year of study and that students who their age ranged from 19 to 20 years represented the highest proportion of participants. Moreover, more than one third of students were studying 11 to 15 or 16 to 20 hours per week. 
Table 1. Student Demographic Information

\begin{tabular}{|c|c|c|c|c|c|}
\hline Variable & Response & $\mathbf{N}(\%)$ & Variable & Response & $\mathbf{N}(\%)$ \\
\hline \multirow{4}{*}{ University } & CRU & $1359(62.6)$ & \multirow{4}{*}{$\begin{array}{l}\text { Program } \\
\text { study }\end{array}$} & Not reported & $597(27.5)$ \\
\hline & WRU & $526(24.2)$ & & Humanities & $570(26.3)$ \\
\hline & ERU & $121(5.6)$ & & Health & $276(12.7)$ \\
\hline & SRU & $165(7.6)$ & & Science & $728(33.5)$ \\
\hline \multirow{2}{*}{ Gender } & Male & $868(40.0)$ & \multirow{2}{*}{ Nationality } & Saudi & $2013(92.7)$ \\
\hline & Female & $1303(60.0)$ & & Non Saudi & $158(7.3)$ \\
\hline \multirow{6}{*}{ Age } & 18 years & $284(13.1)$ & \multirow{6}{*}{$\begin{array}{l}\text { Grade point } \\
\text { average (GPA) }\end{array}$} & Not reported & $674(31.0)$ \\
\hline & $19 \& 20$ years & $911(42.0)$ & & $0.00-1.00$ & $3(0.1)$ \\
\hline & $21 \& 22$ years & $438(20.2)$ & & $1.01-2.50$ & $38(1.8)$ \\
\hline & $23 \& 24$ years & $151(7.0)$ & & $2.51-3.50$ & $251(11.6)$ \\
\hline & 25 to 30 years & $247(11.4)$ & & $3.51-4.50$ & $676(31.1)$ \\
\hline & 31 years $\&$ older & $140(6.4)$ & & $4.51-5.00$ & $529(24.4)$ \\
\hline \multirow{4}{*}{ Education level } & Diploma & $37(1.7)$ & \multirow{4}{*}{$\begin{array}{l}\text { Total study } \\
\text { hours per week }\end{array}$} & 1 hour to 10 hours & $314(14.5)$ \\
\hline & Undergraduate & $1919(88.4)$ & & 11 to 15 hours & $763(35.1)$ \\
\hline & Masters student & $198(9.1)$ & & 16 to 20 hours & $794(36.6)$ \\
\hline & Doctoral student & $17(0.8)$ & & 21 hours \& more & $300(13.8)$ \\
\hline \multirow{5}{*}{ Study year } & First year & $843(38.8)$ & \multirow{5}{*}{$\begin{array}{l}\text { Employment } \\
\text { status }\end{array}$} & & \\
\hline & Second year & $604(27.8)$ & & Not working & $1786(82.3)$ \\
\hline & Third year & $430(19.8)$ & & Working part time & $111(5.1)$ \\
\hline & Fourth year & $226(10.4)$ & & Working full time & $274(12.6)$ \\
\hline & $>4$ years & $68(3.1)$ & & & \\
\hline \multirow{3}{*}{ Study mode } & On campus & $1754(80.8)$ & \multirow{3}{*}{ Study type } & Full time & $1921(88.5)$ \\
\hline & Off campus & $246(11.3)$ & & Part time & $250(11.5)$ \\
\hline & Both modes & $171(7.9)$ & & & \\
\hline
\end{tabular}

\subsection{Usage and Experience of ICT}

Students were asked regarding their frequent use of ICT tools and the responses are shown in Table 2.

Table 2. Frequent Use of ICT Tools

\begin{tabular}{lcccccc}
\hline \multicolumn{1}{c}{ ICT tool } & $\begin{array}{c}\text { Never } \\
\mathbf{N ~ ( \% )}\end{array}$ & $\begin{array}{c}\text { Very rarely } \\
\mathbf{N ~ ( \% )}\end{array}$ & $\begin{array}{c}\text { Rarely } \\
\mathbf{N ~ ( \% )}\end{array}$ & $\begin{array}{c}\text { Often } \\
\mathbf{N ~ ( \% )}\end{array}$ & $\begin{array}{c}\text { Very often } \\
\mathbf{N}(\mathbf{\%})^{\mathbf{a}}\end{array}$ & \multirow{2}{*}{$\mathbf{M}^{\mathbf{b}}(\mathbf{S D})$} \\
\hline Computers & $6(0.3)$ & $18(0.8)$ & $89(4.1)$ & $490(22.6)$ & $1568(72.2)$ & $3.66(0.625)$ \\
Internet & $1(0.0)$ & $5(0.2)$ & $14(0.6)$ & $124(5.7)$ & $2027(93.4)$ & $3.92(0.324)$ \\
Email & $25(1.2)$ & $71(3.3)$ & $203(9.4)$ & $662(30.5)$ & $1210(55.7)$ & $3.36(0.868)$ \\
ODFs & $162(7.5)$ & $318(14.6)$ & $567(26.1)$ & $724(33.3)$ & $400(18.4)$ & $2.41(1.162)$ \\
LMSs & $643(29.6)$ & $280(12.9)$ & $407(18.7)$ & $491(22.6)$ & $350(16.1)$ & $1.83(1.468)$ \\
\hline
\end{tabular}

a. The percentages are out of the total number of participants for each ICT tool.

b. The range was $0=$ Never to $4=$ Very often.

Overall, the data in Table 2 show that the majority of students were using the Internet and computers most frequently, but that the use of more educational tools such LMSs was limited. In addition, more than half of students were often or very often using ODFs.

Students were also asked regarding their experience level of using ICT tools and the responses are shown in Table 3. 
Table 3. Experience Level with ICT Tools

\begin{tabular}{lccccc}
\hline \multicolumn{1}{c}{ ICT tool } & $\begin{array}{c}\text { No experience } \\
\mathbf{N}(\%)^{\mathbf{a}}\end{array}$ & $\begin{array}{c}\text { Little } \\
\mathbf{N ~ ( \% )}\end{array}$ & $\begin{array}{c}\text { Moderate } \\
\mathbf{N}(\%)^{\mathbf{a}}\end{array}$ & $\begin{array}{c}\text { Extensive } \\
\mathbf{N}(\mathbf{\%})^{\mathbf{a}}\end{array}$ & \multirow{2}{*}{$\mathbf{M}^{\mathbf{b}}(\mathbf{S D})$} \\
\hline Computers & $5(0.2)$ & $165(7.6)$ & $1045(48.1)$ & $956(44.0)$ & $3.36(0.630)$ \\
Internet & $1(0.0)$ & $81(3.7)$ & $813(37.4)$ & $1276(58.8)$ & $3.55(0.570)$ \\
Email & $24(1.1)$ & $120(5.5)$ & $719(33.1)$ & $1308(60.2)$ & $3.53(0.653)$ \\
ODFs & $171(7.9)$ & $493(22.7)$ & $853(39.3)$ & $654(30.1)$ & $2.92(0.915)$ \\
LMSs & $719(33.1)$ & $522(24.0)$ & $611(28.1)$ & $319(14.7)$ & $2.24(1.068)$ \\
\hline
\end{tabular}

a. The percentages are out of the total number of participants for each ICT tool.

b. The range was $1=$ No experience to $4=$ Extensive.

Overall, the data in Table 3 reveal that students had great experience of using Internet, email, and computers, respectively. However, they had little experience with using LMSs and appeared to have a moderate experience with using ODFs.

\subsection{Purpose of Using ICT}

Students were also asked regarding the purpose of using ICT tools and the responses are shown in Table 4.

Table 4. Purpose of Using ICT Tools

\begin{tabular}{lccccc}
\hline \multicolumn{1}{c}{ ICT tool } & $\begin{array}{c}\text { NA } \\
\mathbf{N ~ ( \% )}\end{array}$ & $\begin{array}{c}\text { Others } \\
\mathbf{N ~ ( \% )}\end{array}$ & $\begin{array}{c}\text { Entertainment } \\
\mathbf{N ~ ( \% )})^{\mathbf{a}}\end{array}$ & $\begin{array}{c}\text { Health } \\
\mathbf{N ~ ( \% )}\end{array}$ & $\begin{array}{c}\text { Education } \\
\mathbf{N ~ ( \% )})^{\mathbf{a}}\end{array}$ \\
\hline Computers & $5(0.2)$ & $171(7.9)$ & $399(18.4)$ & $22(1.0)$ & $1574(72.5)$ \\
Internet & $2(0.1)$ & $245(11.3)$ & $947(43.6)$ & $51(2.3)$ & $926(42.7)$ \\
Email & $42(1.9)$ & $410(18.9)$ & $133(6.1)$ & $25(1.2)$ & $1561(71.9)$ \\
ODFs & $284(13.1)$ & $360(16.6)$ & $374(17.2)$ & $100(4.6)$ & $1053(48.5)$ \\
LMSs & $811(37.4)$ & $113(5.2)$ & $47(2.2)$ & $19(0.9)$ & $1181(54.4)$ \\
\hline
\end{tabular}

a. The percentages are out of the total number of participants for each ICT tool.

The results in Table 4 show that students were mostly using computers, email, LMSs and ODFs for educational purposes. It was also noticed that Internet was used mainly for entertainment and educational purposes, respectively.

\subsection{Experience with Online Education}

In this study, there were three explicit indicators to student experience with online education as shown in Table 5. Students were asked regarding these variables in the demographic information section of the online survey.

Table 5: Experience with Online Education

\begin{tabular}{|c|c|c|c|c|c|c|}
\hline \multirow{2}{*}{ Variable } & \multicolumn{2}{|c|}{ Previous online courses } & \multicolumn{2}{|c|}{ Experience with online courses } & \multicolumn{2}{|c|}{ Hours per week online } \\
\hline & Response & $\mathbf{N}(\%)$ & Response & $\mathbf{N}(\%)$ & Response & $\mathbf{N}(\%)$ \\
\hline & None & $1615(74.4)$ & Never & $1617(74.5)$ & None & $1756(80.9)$ \\
\hline & 1 to 4 & $316(14.6)$ & $<1$ year & $223(10.3)$ & 1 to 9 & $186(8.6)$ \\
\hline & 5 to 9 & $149(6.9)$ & 1 year & $149(6.9)$ & 10 to 19 & $201(9.3)$ \\
\hline & 10 to 19 & $41(1.9)$ & 2 years & $95(4.4)$ & $20 \&$ more & $28(1.3)$ \\
\hline & $20 \&$ more & $50(2.3)$ & 3 years \& more & $87(4.0)$ & & \\
\hline
\end{tabular}

Table 5 shows that the majority of students had not studied online courses, had no previous experience with online courses, and had no online study load. It can be also extrapolated from Table 5 that 556 students (25.7\%) had studied previous online courses, 554 students $(25.6 \%)$ had experience with online courses, and 415 students (19.2\%) had studying hours per week online. In addition, student study mode in Table 1 was an implied indicator to student experience with online education which indicates that 246 students $(11.3 \%)$ had off campus studying mode. These four indictors together may explain student experience with online education in the four Saudi universities. 


\subsection{Student Satisfaction with Using ODFs}

Students finally were asked regarding their satisfaction with using ODFs in the learning process and the responses are presented in Table 6.

Table 6. Student Satisfaction

\begin{tabular}{lc}
\hline \multicolumn{1}{c}{ Item } & $\mathbf{M}^{\mathrm{b}}$ (SD) \\
\hline I would like to study other courses using online discussion forums & $2.51(0.971)$ \\
I feel a sense of achievement when using online discussion forums & $2.65(0.875)$ \\
I enjoy using online discussion forums & $2.74(0.881)$ \\
I recommend using online discussion forums to other students $^{\text {I feel bored when using online discussion forums }{ }^{\text {a }}}$ & $2.77(0.863)$ \\
I am more satisfied with online discussion forums than face to face discussion $^{\text {The time I spend in online discussion forums would be better spent in face to face class }{ }^{\text {a }}}$ & $2.51(0.907)$ \\
Overall, I am satisfied with online discussion forums $^{\quad \text { Satisfaction scale }}$ & $2.48(0.967)$ \\
\hline
\end{tabular}

a. Reversed.

b. Using Likert scale for agreement with range of $1=$ strongly disagree to $4=$ strongly agree.

Overall, the data in Table 6 indicate that students were satisfied with using ODFs in the learning process $(M=2.59$, $S D=.656)$. Particularly, they agreed to recommend using ODFs to other students and they enjoyed using them in their learning.

\subsection{Relationships between Student Satisfaction with Using ODFs and the Study Variables}

These relationships were examined using bivariate correlation analysis and the correlation coefficients of these relationships are shown in Table 7 and Table 8.

Table 7. Correlations of Demographics

\begin{tabular}{lclclc}
\hline Variable & Satisfaction & \multicolumn{1}{c}{ Variable } & Satisfaction & \multicolumn{1}{c}{ Variable } & Satisfaction \\
\hline Gender & $-.096^{\mathrm{b}}$ & Employment status & $.124^{\mathrm{b}}$ & Study year & $.059^{\mathrm{b}}$ \\
Age & $.218^{\mathrm{b}}$ & Nationality & -.026 & GPA & $-.115^{\mathrm{b}}$ \\
Study mode & $.125^{\mathrm{b}}$ & Program of study & .011 & Total study hours & -.026 \\
Study type & $.203^{\mathrm{b}}$ & Education level & .004 & & \\
\hline
\end{tabular}

a. $P<.05$.

b. $P<.01$.

The results in Table 7 indicate that significant and positive relationships were found with most of the study demographic variables. Older students, studying off campus or both modes students, part time students, worker students, or students in the late study years were more satisfied with using ODFs than other students. The significant and negative relationship with gender $(r=-.096, p<0.01)$ indicates that male students were more satisfied with using ODFs than female students whereas the significant and negative relationship with GPA $(r=-.115, p<0.01)$ indicates that students with less GPAs were more satisfied with using ODFs than students with high GPAs. However, there were no significant relationships between student satisfaction with ODFs and nationality, program of study, educational level, and study load.

Similarly, the results in Table 8 indicate that most of the ICT and online education variables had significant and positive relationships with student satisfaction. The significant and negative relationship with the purpose of using email $(r=-.45, p<0.05)$ indicates that students who were using email for non-educational purposes were more satisfied with using ODFs than those who were using it for educational purposes. However, there were no significant relationships between student satisfaction with ODFs and the frequent use of Internet and email. 
Table 8. Correlations of Experience with ICT and Online Education

\begin{tabular}{|c|c|c|c|c|c|}
\hline Variable & Sat. $^{c}$ & Variable & Sat. $^{c}$ & Variable & Sat. $^{c}$ \\
\hline Frequent $\mathrm{u}$ & $.114^{\mathrm{b}}$ & Experience with computers & $.108^{b}$ & Purpose of using & .033 \\
\hline Frequ & .039 & Experie & $.079^{\mathrm{b}}$ & Purpose of & $.117^{\mathrm{b}}$ \\
\hline Frequent use of email & .036 & Experience with email & $.089^{\mathrm{b}}$ & Purpose of using email & $-.45^{\mathrm{a}}$ \\
\hline Frequent use of ODFs & $.320^{\mathrm{b}}$ & Experience with ODFs & $.254^{\mathrm{b}}$ & Purpose of using ODFs & $.177^{\mathrm{b}}$ \\
\hline Frequent use of LMSs & $.166^{\mathrm{b}}$ & Experience with LMSs & $.184^{\mathrm{b}}$ & Purpose of using LMSs & $.123^{\mathrm{b}}$ \\
\hline Online study hours & $.173^{\mathrm{b}}$ & Previous online courses & $.187^{\mathrm{b}}$ & Experience with online courses & $.177^{\mathrm{b}}$ \\
\hline
\end{tabular}

a. $P<.05$.

b. $P<.01$.

c. Satisfaction

\section{Discussion}

This study aimed to investigate student satisfaction with using ODFs at four Saudi universities. It also examined the relationships between student satisfaction with using ODFs and student demographics as well as with their experience with ICT and online education. The findings indicate that students at Saudi universities are satisfied with using ODFs (see Table 6). This finding supports the work of Alamro and Schofield (2012) and Altaf (2013), who revealed similar findings in the same context. It is also in line with the findings of Shana (2009), who found that students are satisfied with using ODFs alongside traditional learning in another context. Investigation of student experience with ICT reveals that while the use of educational tools such LMSs appears to be limited (see Table 2), the use of other ICT tools in this study seems to be for educational purposes (see Table 4). Students at Saudi universities reported different experience levels with using ICT tools (see Table 3) and that was compatible with their use in general (see Table 2). However, they reported a low level of experience with online education (see Table $5)$.

The relationships between student satisfaction and their demographics were examined. Across the four universities, the findings reveal that older students, studying off campus or both modes students, part time students, worker students, or students in the late study years were more satisfied with using ODFs than other students (see Table 7). The finding that old student and part time students were more satisfied than other students is inconsistent with finding of Ryan (2013) and Jackson (2014), respectively, who found no relationship between student satisfaction with using ODFs and student age or student study type in another context. A high level of life commitments or engaging in the labour market may make those students with these particular demographics more satisfied with using ODFs than others where such obligations are the responsibility of the students. This finding is likely to be attributable to the flexibility in time and location when using ODFs (Al-Ismaiel, 2013; Alamro \& Schofield, 2012; Bye, Smith, \& Rallis, 2009; Cheung, Hew, \& Ling Ng, 2008; Ismail, Mahmood, \& Babiker, 2013).

In the present study, the finding that male students were more satisfied with using ODFs than female students disagrees with the finding of Jackson (2014), who found student satisfaction with using ODFs does not differ based on student gender in another context. This finding is likely to be attributable to the limited home Internet access for female students within the Saudi context (Aldebasi \& Ahmed, 2013; Alhareth, 2013; Miliany, 2014). That is to say, the unavailability of the Internet to female students may make them less satisfied with using ODFs due to the culture restriction.

The findings of the present study also reveal that students with less GPAs were more satisfied with using ODFs than students with high GPAs. This finding dose not align with the finding of Jackson (2014), who found student satisfaction with using ODFs does not differ based on student GPA in another context. Students in the present study had a high degree of traditional learning experience (see Table 5), which may have allowed them to feel that this learning method is better than other methods. This is in line with the assertion regarding the influence of traditional learning on university students in the same context made by Hamdan (2014). In another context, Selwyn (2007) asserted that many university students are compelled to adopt low-level learning methods rather than ICT tools, because "there is simply no time to develop new skills at the risk of jeopardizing work and, ultimately, final examination grades and degree classifications" (p. 89). That means, while higher student engagement in ODFs is likely to increase student satisfaction (AlJeraisy et al., 2015; AlMahamoud \& Elebiary, 2013), excellent student preference of traditional learning may make them less satisfied with other forms of learning. Student preference of 
traditional learning was found to be one of the dimensions that limits their engagement in ODFs in the same context (Al-Ismaiel, 2013).

The findings of the present study also reveal that student demographics include nationality, program of study, educational level, and study load had no relationships with student satisfaction with ODFs. However, examining the relationships between student satisfaction with using ODFs and their experience with ICT and online education reveals that students increased experience of ICT and online education seems to make them more qualified to work with ODFs and, in turn, that makes them satisfied with using ODFs in general. This finding somewhat contrasts Ryan (2013) findings, who found that computer expertise did not relate to student satisfaction with ODFs. However, this finding intensifies the relationship between student satisfaction with using ODFs and the number of previous online courses as found by Jackson (2014) and Ryan (2013) in another context. This finding of the present study is also in agreement with previous research in the same context (AlJeraisy et al., 2015; AlMahamoud \& Elebiary, 2013; Hamdan, 2014), which has indicated that student engagements in ODFs made them more successful and increased their satisfaction with the learning experience, as well as with the LMSs. More engagement in ODFs does not only affect ICT experience for this particular tool, but it also affects online educational experience, since the use of these tools is for educational purposes. It is expected that a higher use of ODFs is likely to lead students to become more satisfied with it, as found with using the Internet by Goyal, Purohit, and Bhaga (2011) in another context. Overall, these results indicate that the experience of ICT and online education appears to have caused students to become satisfied with using ODFs in the present study, although their experience with online education in particular was not high.

\section{Limitation, Future Directions and Implications}

It would be interesting to see which university students were more satisfied and why, but due to the ethical considerations doing so with pseudonyms would not generate any helpful results. Future research should take into account such ethical limitation in order to make the results more useful and ethical. In this study, it was found that using email for non-educational purposes had a significant and positive relationship with student satisfaction with using ODFs for educational purposes (Table 8) which makes further investigation of the reasons behind this unexpected finding would be interesting. According to the results of this study, experience with ICT and online education plays a major role in the satisfaction levels of students. Therefore, training in the effective use of ICT tools, particularly for online activities, is recommended for students, so that they can use ODFs more effectively for pedagogical purposes. The Saudi community must become aware of the benefits brought by the Internet, particularly in the educational field (e.g. see, Alturise \& Alojaiman, 2013). Therefore, the responsible person in each family within the Saudi context should allow their family members to access the Internet at any time, while still monitor their usage. If equal access to the Internet is offered for both genders, using ODFs in blended learning courses might be perceived as being more effective and satisfactory for university students regardless of their gender.

\section{Conclusion}

Students across the four Saudi universities were satisfied with using ODFs in their learning. The relationships between student satisfaction with using ODFs and student demographics as well as with their experience with ICT and online education were examined and discussed. The availability of the Internet, preference of traditional learning, life commitments, and experience with ICT and online education are to be considered when applying to use ODFs effectively and satisfactorily.

\section{Acknowledgements}

This study was funded by the Ministry of Higher Education in Saudi Arabia. The author would like to thank his colleagues and the administrative staff who facilitated the data collection process. The author would like also to thank the research participants who kindly and voluntarily agreed to participate in this study.

\section{References}

Abou Naaj, M., Nachouki, M., \& Ankit, A. (2012). Evaluating student satisfaction with blended learning in a gender-segregated environment. Journal of Information Technology Education: Research, 11, 185-200.

Al-Ismaiel, O. A. (2013). Collaborative blended learning with higher education students in an Arabic context. Unpublished doctoral dissertation, University of Wollongong, Wollongong, New South Wales, Australia. 
Alamro, A. S., \& Schofield, S. (2012). Supporting traditional PBL with online discussion forums: A study from Qassim Medical School. Medical Teacher, 34, 20-24. https://doi.org/10.3109/0142159X.2012.656751

Aldebasi, Y. H., \& Ahmed, M. I. (2013). Computer and Internet utilization among the medical students in Qassim University, Saudi Arabia. Journal of Clinical and Diagnostic Research, 7(6), 1105-1108. https://doi.org/10.7860/jcdr/2013/5891.3092

Alebaikan, R., \& Troudi, S. (2010). Online discussion in blended courses at Saudi Universities. Procedia - Social and Behavioral Sciences, 2(2), 507-514. https://doi.org/10.1016/j.sbspro.2010.03.054

Algahtani, A. F. (2011). Evaluating the effectiveness of the e-learning experience in some universities in Saudi Arabia from male students perceptions. Unpublished doctoral dissertation, Durham University, Durham, England, United Kingdom.

Alhareth, Y. A. (2013). E-learning contribution to the enhancement of higher education opportunities for women in Saudi Arabia (Pilot study). US-China Education Review A, 3(9), 637-648.

AlJeraisy, M. N., Mohammad, H., Fayyoumi, A., \& Alrashideh, W. (2015). Web 2.0 in education: The impact of discussion board on student performance and satisfaction. The Turkish Online Journal of Educational Technology, 14(2), 247-259.

AlMahamoud, S., \& Elebiary, H. (2013, March). Students outcomes \& satisfaction in classical \& blended courses: Comparison study. Paper presented at the Society for Information Technology \& Teacher Education International Conference, New Orleans, Louisiana, United States.

Altaf, E. A. (2013). Online instruction in Saudi Arabian universities: Attitudes and satisfaction towards e-learning systems. Unpublished doctoral dissertation, The University of Newcastle, Newcastle, New South Wales, Australia.

Alturise, F., \& Alojaiman, B. (2013). Benefits and challenges of using ICT in Saudi Arabia universities: A literature review. International Journal of Information Technology \& Computer Science, 11(2), 46-55.

Alzahrani, M. G. (2017). The effect of using online discussion forums on students' learning. Turkish Online Journal of Educational Technology, 16(1), 164-176.

Bolliger, D. U., \& Wasilik, O. (2009). Factors influencing faculty satisfaction with online teaching and learning in higher education. Distance Education, 30(1), 103-116. https://doi.org/10.1080/01587910902845949

Bryman, A. (2012). Social research methods (4th ed.). New York: Oxford University Press.

Bye, L., Smith, S., \& Rallis, H. (2009). Reflection using an online discussion forum: Impact on student learning and satisfaction. Social Work Education, 28(8), 841-855. https://doi.org/10.1080/02615470802641322

Carver, R. H., \& Nash, J. G. (2012). Doing data analysis with SPSS version 18. Boston: Richard Stratton.

Cheung, W. S., Hew, K. F., \& Ling Ng, C. S. (2008). Toward an understanding of why students contribute in asynchronous online discussions. Journal of Educational Computing Research, 38(1), 29-50. https://doi.org/10.2190/EC.38.1.b

Colbran, S., \& Al-Ghreimil, N. (2013). The role of information technology in supporting quality teaching and learning. In L. Smith \& A. Abouammoh (Eds.), Higher education in Saudi Arabia: Achievements, challenges and opportunities (pp. 73-82). Dordrecht, Netherlands, Europe: Springer. https://doi.org/10.1007/978-94-007-6321-0_7

Connolly, P. (2007). Quantitative data analysis in education: A critical introduction using SPSS. New York: Routledge.

Denscombe, M. (2007). The good research guide: For small-scale social research projects (3rd ed.). Maidenhead, Berkshire, United Kingdom: Open University Press.

Field, A. P. (2009). Discovering statistics using SPSS (3rd ed.). London: Sage.

Garnham, C., \& Kaleta, R. (2002). Introduction to Hybrid Courses. Teaching with Technology Today, 8(6). Retrieved from http://www.uwsa.edu/ttt/articles/garnham.htm

Goyal, E., Purohit, S., \& Bhaga, M. (2011). Study of satisfaction and usability of the Internet on student's performance. International Journal of Education and Development using Information and Communication Technology, 7(1), 110-119. 
Hamdan, A. (2014). The reciprocal and correlative relationship between learning culture and online education: A case from Saudi Arabia. International Review of Research in Open \& Distance Learning, 15(1), 309-336. https://doi.org/10.19173/irrodl.v15i1.1408

Ismail, A. O., Mahmood, A. K., \& Babiker, A. E. (2013). Computer labs: Training undergraduate students on an online lab by using asynchronous discussion forum as an online learning tool. International Journal of Scientific and Engineering Research, 4(11), 1109-1114.

Jackson, T. L. (2014). The relationship between student perceptions of satisfaction of social, teaching, and cognitive presence with asynchronous communication tools for online learning in a region $v$ community college. Unpublished doctoral dissertation, West Virginia University, Morgantown, West Virginia, United States.

Kardo, J. M. (2015). Reaching all through open and distance learning in Tanzania. Chanakya International Journal of Business Research, 1(1), 68-78. https://doi.org/10.15410/cijbr/2015/v1i1/61407

Ladyshewsky, R. K. (2013). Instructor presence in online courses and student satisfaction. International Journal for the Scholarship of Teaching and Learning, 7(1), 1-23. https://doi.org/10.20429/ijsotl.2013.070113

Lang, M., \& Costello, M. (2009, April). An investigation of factors affecting satisfactory student learning via on-line discussion boards. Paper presented at the m-ICTE 2009 Conference, Lisbon, Portugal.

Laumakis, M., Graham, C., \& Dziuban, C. (2009). The sloan-c pillars and boundary objects as a framework for evaluating blended learning. Journal of Asynchronous Learning Networks, 13(1), 75-87.

Miliany, K. (2014). The use of TV and the Internet in the social context. International Journal of Social, Education, Economics and Management Engineering, 8(10), 3160-3167.

Moore, J. C. (2005). The sloan consortium quality framework and the five pillars. Newburyport, MA: Sloan Consortium.

Moore, M., \& Kearsley, G. (2012). Distance education: A systems view of online learning (3rd ed.). Belmont, CA: Wadsworth Cengage Learning.

Pallant, J. F. (2011). SPSS survival manual: A step by step guide to data analysis using SPSS (4th ed.). Crows Nest, NSW, Australia: Allen \& Unwin.

Ryan, R. S. (2013). The effect of online discussion forums on student learning and student perception of learning in a science course at the community college level. Unpublished doctoral dissertation, The University of Southern Mississippi, Hattiesburg, Mississippi, United States.

Selwyn, N. (2007). The use of computer technology in university teaching and learning: A critical perspective. Journal of Computer Assisted Learning, 23(2), 83-94. https://doi.org/10.1111/j.1365-2729.2006.00204.x

Shana, Z. (2009). Learning with technology: Using discussion forums to augment a traditional-style class. Journal of Educational Technology \& Society, 12(3), 214-228.

Skelton, D. J. E. (2007). An investigation into the learning environments of blended delivery (e-learning and classroom) in a tertiary environment. Unpublished doctoral thesis, Curtin University of Technology, Perth, Western Australia, Australia.

Sue, V. M., \& Ritter, L. A. (2007). Conducting online surveys. Thousand Oaks, CA: Sage. https://doi.org/10.4135/9781412983754

Swan, K. (2001). Virtual interactivity: Design factors affecting student satisfaction and perceived learning in asynchronous online courses. Distance Education, 22(2), 306-331. https://doi.org/10.1080/0158791010220208

Swan, K., \& Shih, L. F. (2005). On the nature and development of social presence in online course discussions. Journal of Asynchronous Learning Networks, 9(3), 115-136. 